\title{
INTESTINAL VASCULAR LESIONS SIMULATING POLYARTERITIS NODOSA AFTER RESECTION OF COARCTATION OF THE AORTA
}

\author{
BY \\ R. L. HURT AND W. J. HANBURY \\ From St. Bartholomew's Hospital, London
}

(RECEIVED FOR PUBLICATION MAY 9, 1957)

It is only recently that mesenteric arterial necrosis, causing severe abdominal symptoms, has been recognized as a post-operative complication after resection of coarctation of the aorta. The first recorded case was mentioned briefly in a report by Sealy (1953) and later presented in detail, together with another similar case, by Benson and Sealy (1956). Two further cases, with lesions indistinguishable from periarteritis nodosa, were reported by Lober and Lillehei (1954), and another by Perez-Alvarez and Oudkerk (1955). No other cases have been reported in the literature, although Ring and Lewis (1956) have reviewed a series of 18 patients in whom abdominal symptoms of varying intensity occurred as a marked feature during the post-operative period. Cleland, Counihan, Goodwin, and Steiner (1956) have also reported the occurrence of severe post-operative abdominal pain in five out of a series of 40 cases of coarctation treated surgically, but came to no conclusion as to the cause of the pain.

Patients who develop abdominal pain after a resection of a coarctation of the aorta may be treated on a more rational basis if it is recognized that this pain, which can be severe and of sufficient severity to simulate an acute abdominal emergency, may be due to arterial necrosis. The condition also has added significance in relation to the role of haemodynamics in the aetiology of polyarteritis nodosa and related arterial diseases. For these reasons a further case with striking pathological changes is presented in this paper.

\section{CASE History}

A 10-year-old boy had been known to have coarctation of the aorta since the age of 5, after the incidental discovery of a precordial systolic murmur. The child had led a normal, healthy, and active life, and there had been no appreciable symptoms. There was no history of allergy, although two grandparents and a brother had suffered from asthma.
Clinical examination showed that the brachial bloodo pressures were $148 / 102 \mathrm{~mm} . \mathrm{Hg}$ (right side) and 156/112 $\mathrm{mm}$. $\mathrm{Hg}$ (left side). No pulsation could be felt in the $\vec{c}$ abdominal aorta or in either lower limb. Abnormald arterial pulsation could be felt in the chest wall in the posterior axillary line on both sides, indicating the 3 presence of a collateral circulation. A systolic murmuro was audible all over the precordium, maximal in the third left interspace and faintly conducted into the neck. A $\overrightarrow{0}$ chest radiograph showed notching of several ribs on both $Y$ sides, from the third rib downwards. An electrocardiegram showed evidence of considerable left ventricue hypertrophy. The haemoglobin was $13.9 \mathrm{~g}$. per $100 \mathrm{~m}$. S and the white blood cell count was 12,200 per c.mm.
abnormality was found in the urine. The coarctation was resected by Mr. O. S. Tubbs on July 19, 1956. Systemic penicillin was given pre- and $\overrightarrow{\vec{P}}$ post-operatively. During the operation the blood $\frac{0}{3}$ pressure was maintained around $100 \mathrm{~mm}$. $\mathrm{Hg}$ systolic $\frac{}{\sigma}$ by the use of an intravenous infusion of " arfonad." The coarctation was found at the site of attachment of the ligamentum arteriosum and the obstruction was almost complete, no pulsation being visible below the narrowed segment. A fair collateral circulation had developed, as $\widetilde{x}$ shown by enlargement of the intercostal arteries and left $\dot{\sigma}-$ internal mammary artery, and also by the large vessels . in the chest wall. The coarctation was resected and an $\delta$ end-to-end anastomosis of the adjacent portions of the aorta performed. There was only a minimal degree of $\mathrm{O}$ constriction at the site of anastomosis. The operation was completed in four hours, and the patient's condition $\frac{7}{2}$ on return to the ward was satisfactory, both femoral pulses being easily palpable.

For 17 days after operation the blood pressure remained in the region of $180 / 130 \mathrm{~mm}$. Hg. On the third $\widetilde{N}$ post-operative day the patient began to complain of $\mathbb{N}^{N}$ abdominal pain and distension. This pain was general- $\bar{O}$ ized throughout the abdomen and was in the nature of a colic. The pain and distension continued until the seventeenth day when the patient's condition suddenly deteriorated, the pain became more severe, and signs of a severe intra-abdominal haemorrhage developed. Although up to this time the bowels had been opened $\frac{\vec{d}}{\mathbb{Q}}$

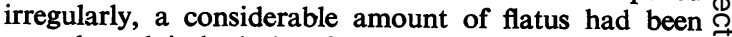
passed, and it had therefore been considered unlikely $\underset{\square}{\mathbb{Q}}$ 
that an acute intestinal obstruction had caused the patient's symptoms. The white blood count had risen to 19,800 per c.mm. A laparatomy was performed and about $1 \frac{1}{2}$ pints of blood were found in the peritoneal cavity. There were numerous nodules throughout the mesenteric blood vessels and one of these had ruptured into the mesentery causing an extensive haematoma which had then burst through into the peritoneal cavity. This bleeding had also extended into the wall of the adjacent segment of small intestine measuring about 8 in. in length. Other parts of the small intestine showed areas of slight greyish discoloration and numerous new blood vessels had developed under the serosa of the small intestine adjacent to the mesenteric nodules. The haemorrhagic portion of intestine was excised and an end-to-end anastomosis performed.

During the following two weeks the blood pressure gradually fell to about $140 / 100 \mathrm{~mm}$. Hg. Colicky abdominal pain of gradually decreasing severity continued, together with considerable abdominal distension. Profuse diarrhoea occurred one week after the intestinal resection, and a week later a faecal fistula developed through the abdominal wound. This fistula closed spontaneously 10 days later. Occasional bouts of intestinal colic continued until the time of the patient's discharge from hospital.

Within a few days the patient was admitted to another hospital with a diagnosis of acute intestinal obstruction, and a further laparotomy was performed on October 1, 1956. Numerous adhesions were present and inadvertently the bowel was damaged, necessitating the resection of a short length of ileum. The subsequent convalescence was uneventful.

\section{Pathology}

The specimen from the first laparotomy consisted of a portion of small intestine measuring $25 \mathrm{~cm}$. in length (after fixation), together with some attached mesentery. A large amount of blood clot was found in the subserous layer over most of the length of the specimen, and there was also considerable haemorrhage into the mesentery. When the bowel was divided along its long axis the lumen was found to be narrowed by the subserous haemorrhage (Fig. 1), but no part appeared necrotic or gangrenous. At the mesenteric border of the intestine many of the terminal branches of the mesenteric artery showed numerous small aneurysms which measured up to $0.6 \mathrm{~cm}$. in diameter and contained recent thrombi.

\section{HistologY}

Sections of the terminal mesenteric arteries showed aneurysmal dilatation, occlusion by recent thrombi and an intense necrotizing arteritis (Fig. 2). The normal architecture of the vessel walls had been entirely lost and replaced by fibrinoid material and cellular inflammatory exudate consisting mostly of neutrophil polymorphs. Sections of the bowel wall also showed a similar necrotizing arteritis affecting many of the submucous vessels (Figs. 3 to 6).

The normal architecture of these vessels was largely replaced by fibrinoid material intermingled with red blood cells and inflammatory cells. The inflammatory exudate, which consisted of large numbers of neutrophil polymorphs with lesser numbers of eosinophils and histiocytes, extended widely around the affected arteries. Perivascular proliferation of fibroblasts was also evident. Thrombi and aneurysmal dilatations were seen occasionally and fragmentation of the internal elastic lamina (Fig. 5) was another feature. The necrotizing process was sometimes seen to be focal, affecting only part of a vessel wall (Fig. 6), while some of the submucous arteries and arterioles appeared to be completely normal. The veins also showed comparatively little involvement (Figs. 4 and 6). The gut wall itself showed no evidence of infarction, the mucosa being well preserved and free from ulceration.

A histological section of the portion of ileum removed at the second laparotomy (eight weeks after the first intestinal resection) was examined and showed medial muscular hypertrophy of the submucous arteries, but no changes resembling healed or recent polyarteritis nodosa. There was also evidence of a resolving peritonitis, but the bowel wall itself appeared healthy with no suggestion of old or recent infarction.

\section{Discussion}

The aetiology of the arterial necrosis in the five cases previously reported and referred to earlier has already been extensively discussed by the authors concerned. The sudden increase in the blood pressure, together with the occurrence of a hypersensitivity reaction, have been thought to be definite factors in the production of the lesion. Lober and Lillehei, in commenting on their two cases, conclude that

" the sudden increase in intravascular strain appears to have been the precipitating influence in producing the arteritis in these cases. It is evident that the changes in arterial blood pressure after coarctation repair must be accompanied by an abnormal response of the patient to produce a necrotizing arteritis. Hypersensitivity may be one factor in this altered response."

Perez-Alvarez and Oudkerk, in discussing their case, state that

" the sudden release of a high pulsating pressure, to which the vessels below the coarcted area had not been subjected, represents trauma. In the case reported, the abdominal vessels responded to this trauma with necrosis which was localized to the media of the small arteries and arterioles."

Benson and Sealy interpret the arterial necroses in their cases

" to be the result of changes in circulatory dynamics following the resection of the coarctation. Perhaps the most important of these are the sudden increase in systolic pressure and the change in character of the pulse wave."

In support of the view that changes in circulatory dynamics are responsible for the necrotic arterial lesions is the fact that in the three cases that came 


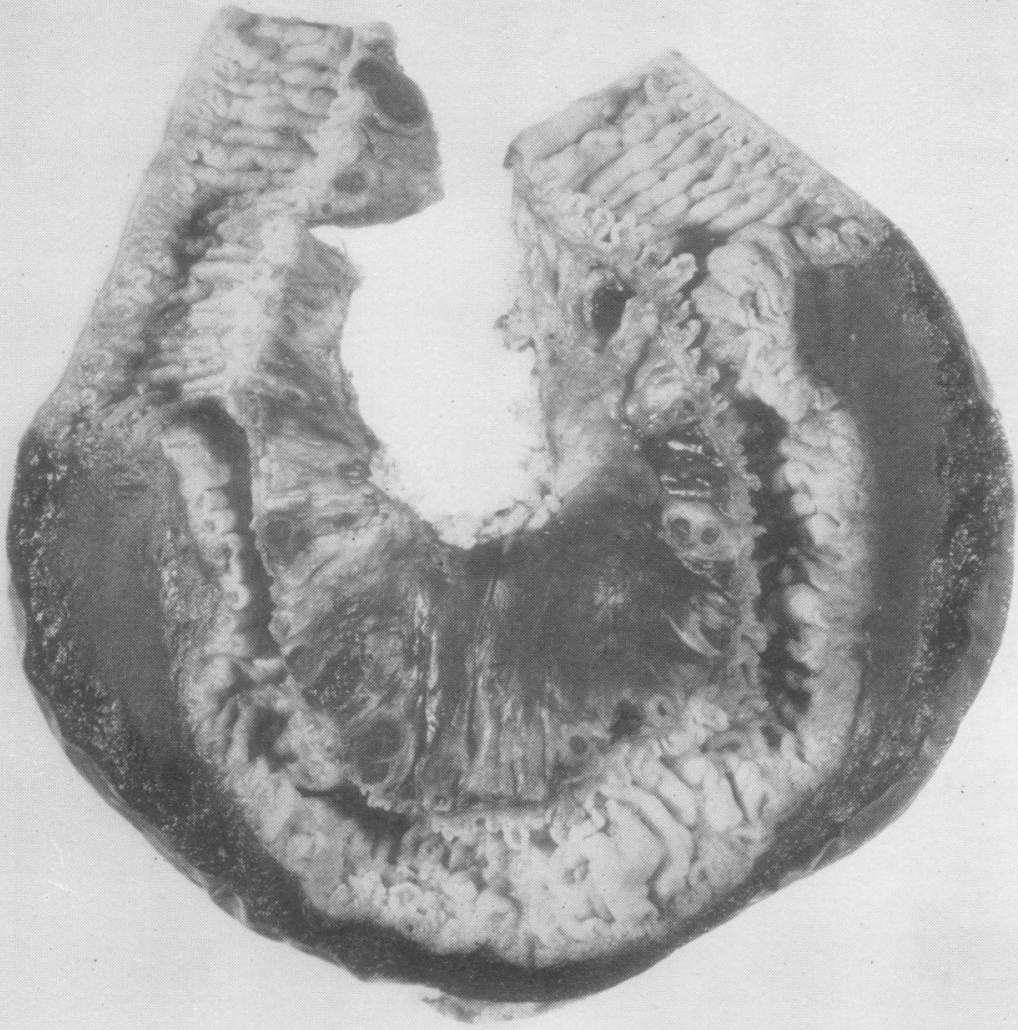

FIG. 1.-The excised portion of small intestine, sect tioned to show extensive subserous aשd mesenteric haemorrhaf with narrowing of the bowellumen. Aneury mal dilatation afid thrombosis of the termo nal mesenteric arterea branches can also be seen.

$\stackrel{\text { be }}{0}$

FIG. 2.-Section of 유ำ intestine shor aneurysmal dilateriog, thrombosis, and neram tizing arteritis of mese teric vessels. The inflammatory process also be seen involvi the small submuco arteries. (Haematoxy and $\operatorname{eosin} \times 8$.)

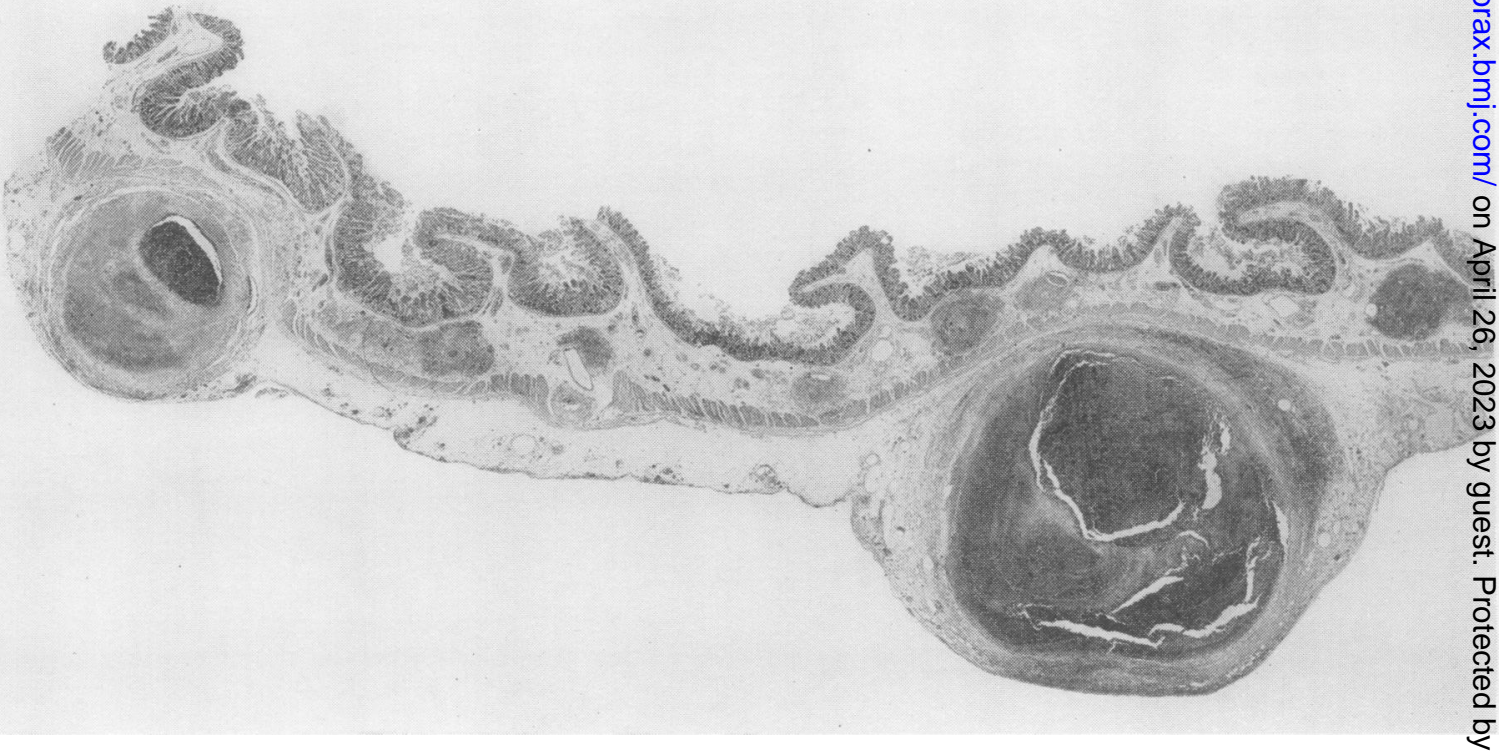




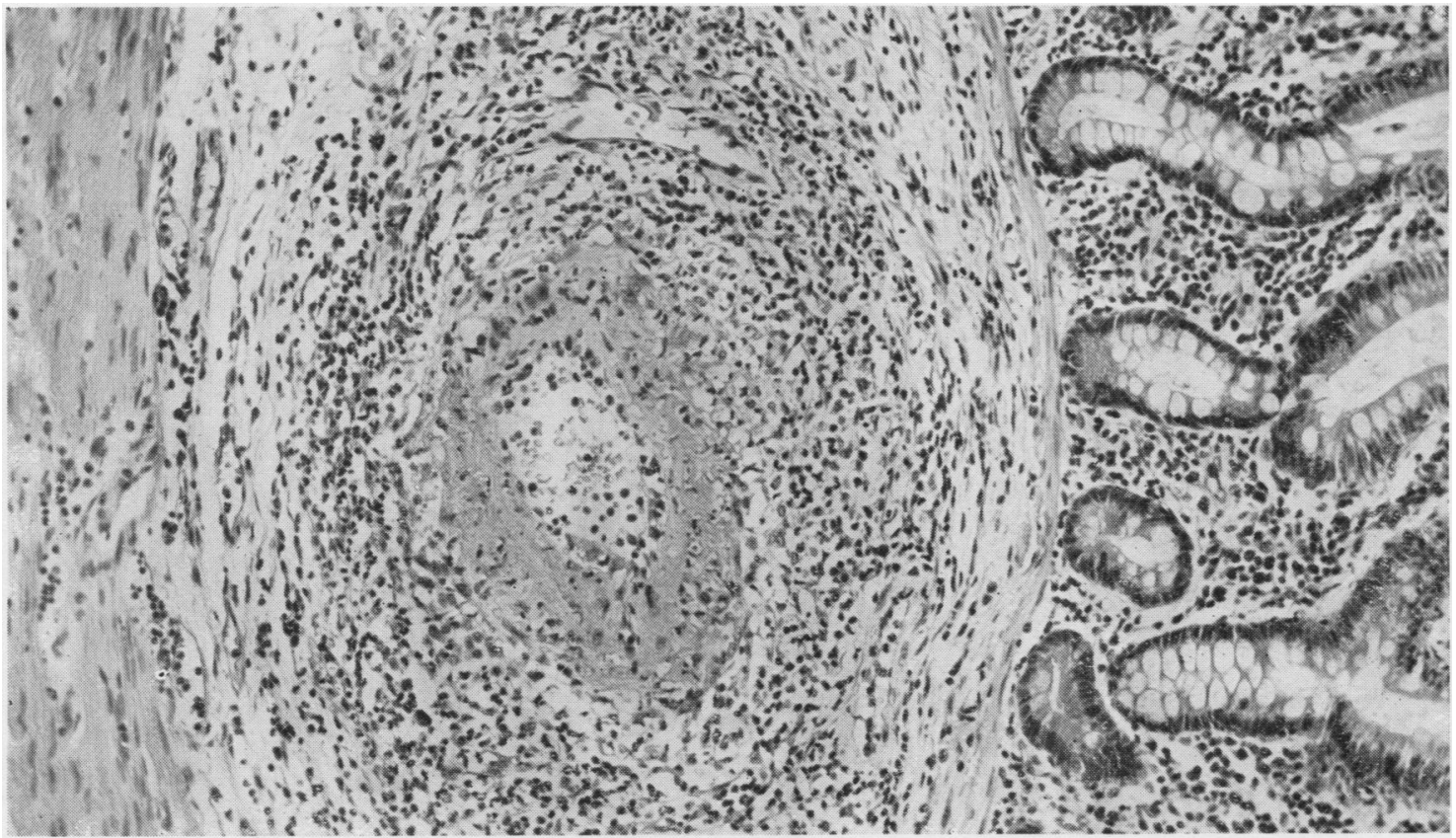

FIG. 3.-Necrotizing arteritis affecting a submucous vessel. (Haematoxylin and eosin $\times 105$.)

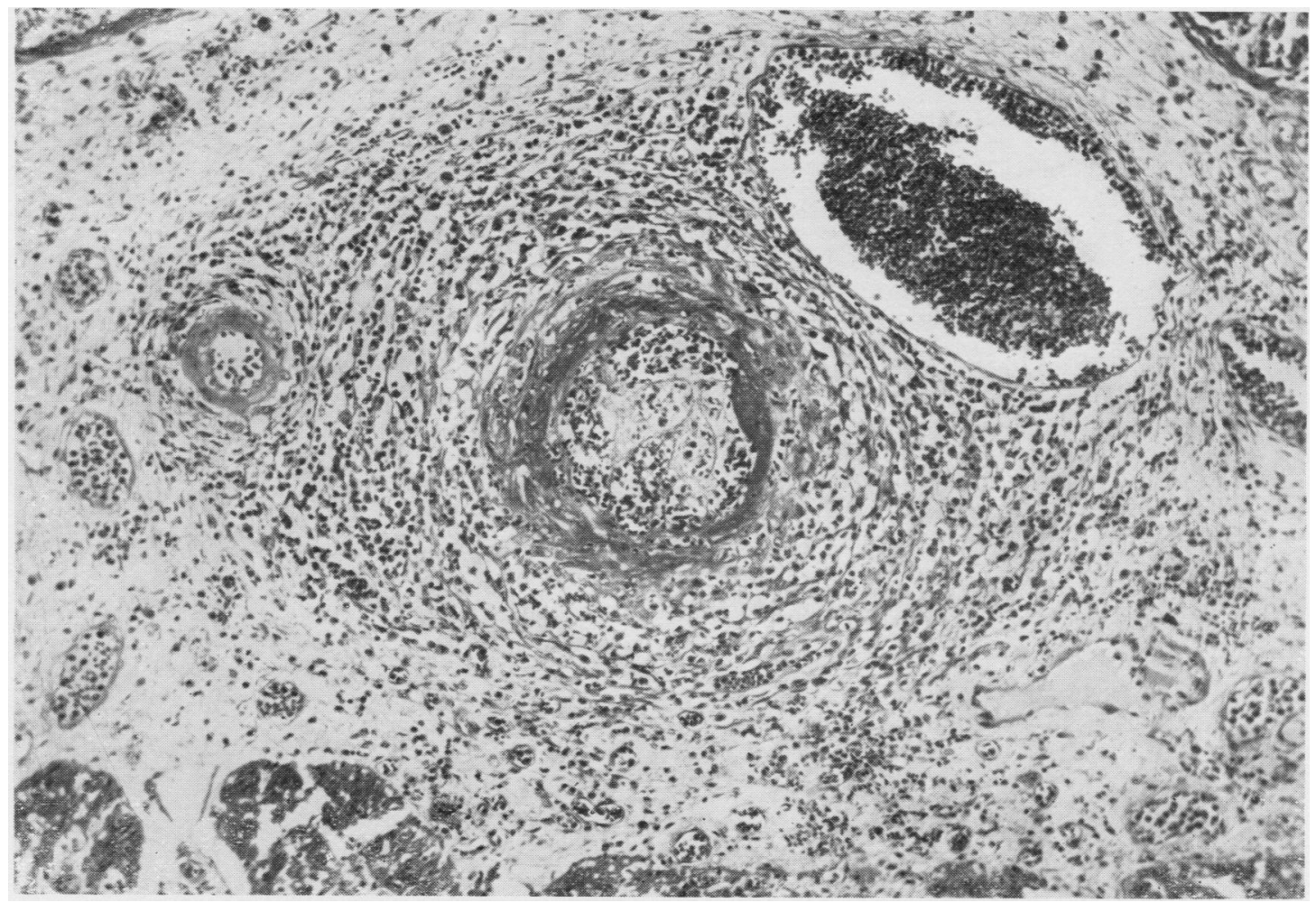

FIG. 4.-Necrotizing arteritis affecting a submucous artery with little involvement of the accompanying vein. (Haematoxylin 


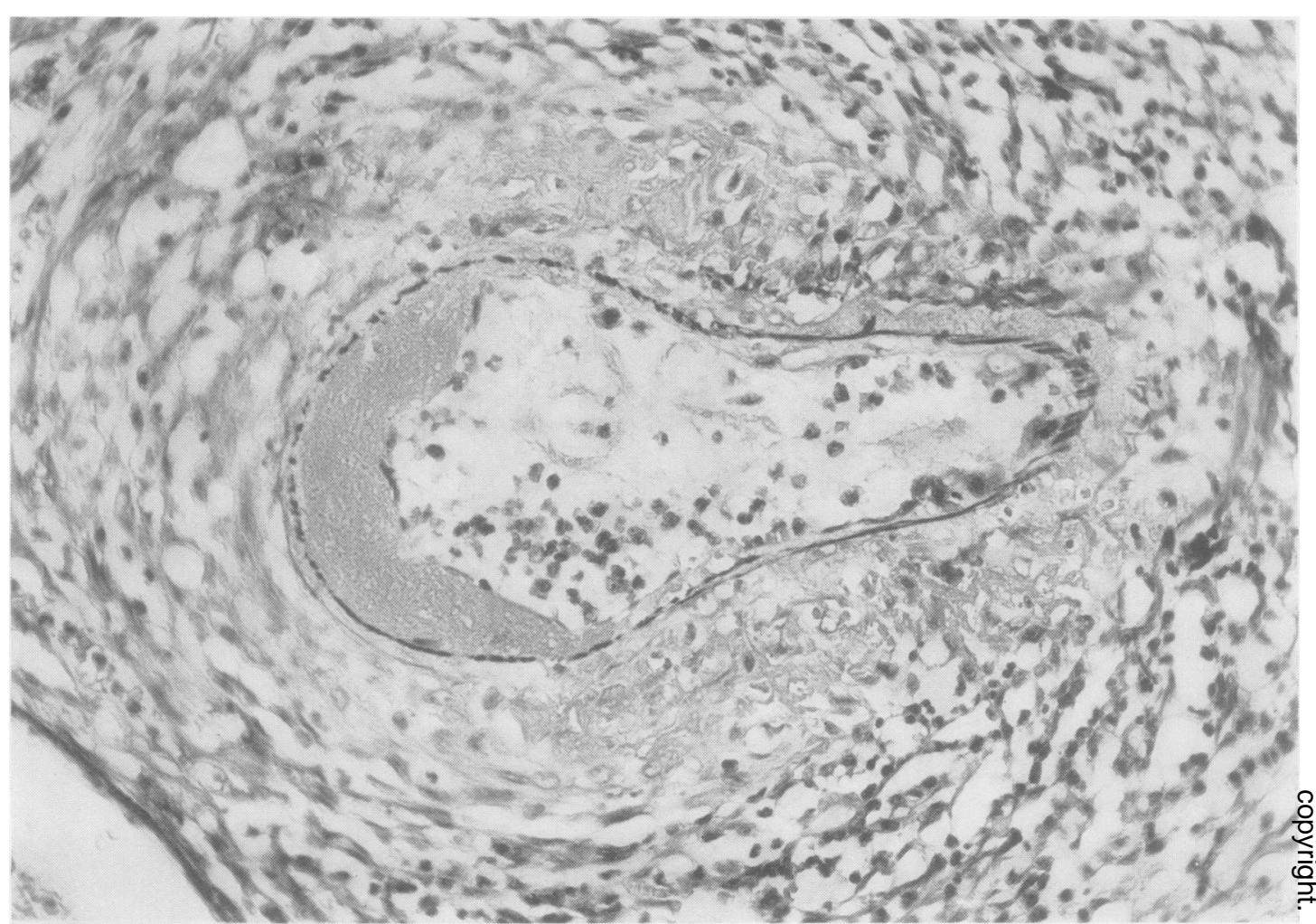

Fig. 5.-A submucous artery showing aneurysmal dilatation and fragmentation of the internal elastic lamina. (Weigert's elastic and van Gieson's stains $\times 350$.)

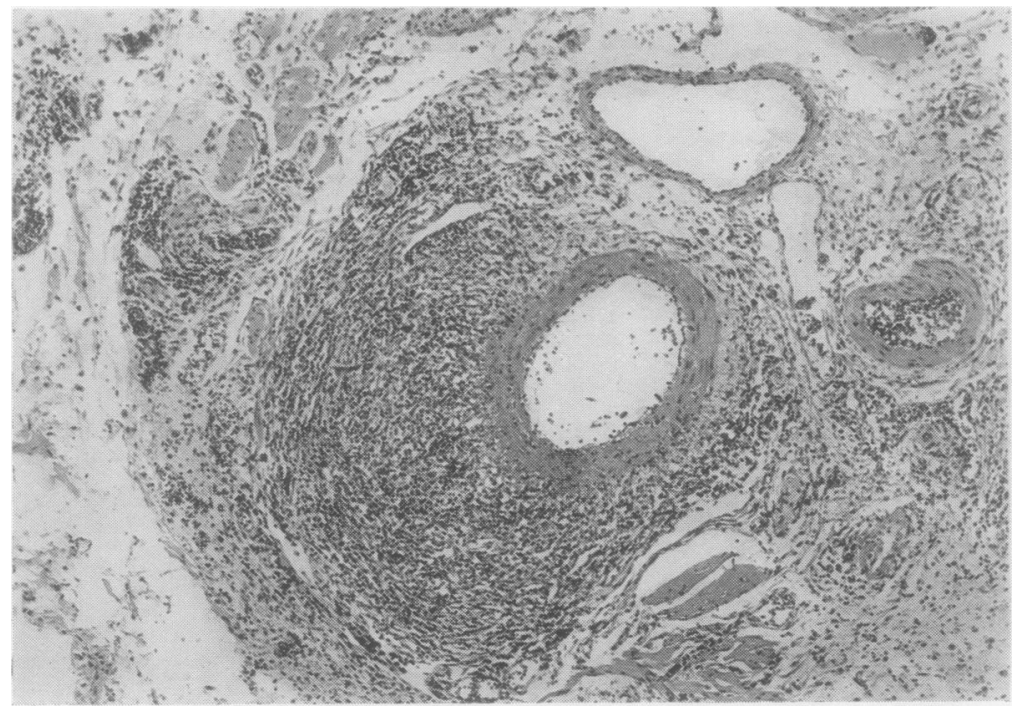

FiG. 6.-A subserous artery showing focal inflammatory necrosis. The accompanying vein is unaffected. (Haematoxylin and eosin $\times 60$.) 
to necropsy the lesions were limited to the vessels originating distal to the coarctation repair (Lober and Lillehei; Perez-Alvarez and Oudkerk; Benson and Sealy). As regards the actual changes in brachial arterial blood pressures before and after operation, Ring and Lewis found that "generally the patients developing abdominal complications seemed to have an earlier and more marked drop in pressure." This is not apparent, however, in the five cases of arterial necrosis revealed at laparotomy, and in the present case the brachial blood pressures actually rose after resection of the coarctation and only fell slowly after the subsequent laparotomy.

The present case does not differ in any great respect from the five previously reported; although areas of greyish discoloration were seen in the small intestine at operation, no infarction was demonstrated pathologically in spite of the extensive vascular lesions. All the other five reported cases showed intestinal infarction of varying degree. Another interesting feature of the present case is the focal nature of the arterial necrosis, some vessels showing involvement of only parts of their walls. This was also noted by Lober and Lillehei in their cases.

Perhaps the most striking feature in the present case is the close resemblance of the arterial lesions to those found in polyarteritis nodosa. Although no definite conclusions can be drawn, the evidence provided by this post-operative complication must lend weight to the idea that excessive vascular strain plays some part in the aetiology of polyarteritis nodosa.

The occurrence of arterial necrosis as a complication of an operation for coarctation of the aorta is of considerable clinical importance. As previously stated, the abdominal pain that may occur may be of such severity as to simulate an acute abdominal emergency, with the result that several of the reported cases have undergone a laparotomy with negative findings. Operation is necessary only if an intraperitoneal haemorrhage occurs, as in the case reported, or if the arterial necrosis is of such severity as to lead to a localized area of gangrene and consequent perforation.

In 17 consecutive cases of resection of coarctation of the aorta, there have been two patients in whom severe abdominal pain has developed post-operatively. One of these patients has been described in detail above, and the second patient, aged 12 years whose pre operative blood pressure was $190 / 100 \mathrm{~mm}$. $\mathrm{Hg}$ and in whom the blood pressure remained elevated for several days after operation, developed marked abdominal pain three days post-operatively. This pain was aching in character and was sufficiently severe to cause considerable concern. The pain subsided spontaneously during the following week and has not recurred during the two years since operation. It is highly probable that the pain was due to the development of areas of arterial necrosis consequent on the continued elevation of blood pressure in the mesenteric vessels.

In those cases in whi $\mathrm{h}$ the blood pressure remains elevated following a successful operation for coarctation of the aorta, the use of a hypotensive drug such as "arfonad" may be advisable in order to reduce the blood pressure and prevent the occurrence of arterial necrosis in the distal vessels due to their sudden exposure to a high blood pressure. It has been noted by Brock (1957) that reactive hypertension may occur post-operatively after the use of " arfonad" during operation, but this observation would not seem to preclude the use of this or any other hypotensive drug during the post-operative period if the blood pressure remains elevated.

\section{SUMMARY}

A case of intestinal arterial necrosis and haemorrhage after operative repair of coarctation of the aorta is described. Only five similar cases were found in the literature, and these are briefly reviewed. The condition is considered to be of importance both on account of its clinical implications and because of the close resemblance of the lesions to those of polyarteritis nodosa.

We should like to thank Mr. O. S. Tubbs for his permission to publish this case and for his most valuable criticism. We are also grateful to Professor J. W. S. Blacklock for his helpful advice, to Mr. N. K. Harrison for the photograph of the small intestine, to Mr. J. W. Miller for histological sections, and to Dr. G. S. Sansom for the photomicrographs.

\section{REFERENCES}

Benson, W. R., and Sealy, W. C. (1956). Lab. Invest., 5, 360. Brock, R. C. (1957). Guy's Hosp. Rep., 106. 131. Cleland, W. P., Counihan, T. B., Goodwin, J. F., and Steiner, R. E. (1956). Brit. med. J., 2, 379.

Lober, P. H., and Lillehei, C. W. (1954). Surgery, 35, 950.

Perez-Alvarez, J. J., and Oudkeik, S. (1955). Ibid., 37, 833.

Ring, D. M., and Lewis, F. J. (1956). J. thorac. Surg., 31, 718.

Sealy, W. C. (1953). Surg. Gynec. Obstet., 97, 301. 